\title{
A materialidade do sagrado nas danças dramáticas indianas
}

The materiality of the sacred in India's dramatic dances

Irani da Cruz Cippiciani ${ }^{1}$

Marilia Vieira Soares ${ }^{2}$ 


\section{Resumo}

Este artigo visa refletir sobre a contribuição da doutrina espiritual hindu para o estabelecimento de parâmetros práticos de experiência com o sagrado nas diferentes danças dramáticas indianas, tomando o corpo do intérprete como veículo de manifestação da experiência estética e espiritual. Para realizar tal análise, nos debruçaremos sobre a relação mestre-discípulo e o conceito de Linhagem; a relação entre Mitologia e Religião; a organização do repertório tradicional, até chegar ao treinamento e a construção corporal, gestual e facial que caracterizam estas manifestações. $O$ principal referencial teórico vem do Natyasastra, complementado pela experiência pessoal dos autores, por quase duas décadas, com as danças dramáticas indianas.

Palavras-chave: Índia; TradiçãoSagrado; Corpo como veículo; DançaDramática; Treinamento Corporal

\section{Abstract}

This article aims to reflect on the contribution of Hindu spiritual doctrine to establish practical parameters of experience with the sacred in different Indian dramatic dances, taking the artist's body as a vehicle of manifestation of aesthetic and spiritual experience. To perform this analysis, we will look on the master-disciple relationship and the concept of Lineage; the relationship between Mythology and Religion; the organization of traditional repertoire, until reach to the training methods and body, facial and gestural construction that characterize these artistic events. Our main theoretical reference comes from Natyasastra, complemented by personal experience of the authors with the dramatic dances for nearly two decades.

Keywords: India; Tradition-Sacred; Body as Vehicle; Dance Drama; Body Trainning 


\section{Natyasastra: o quinto Veda}

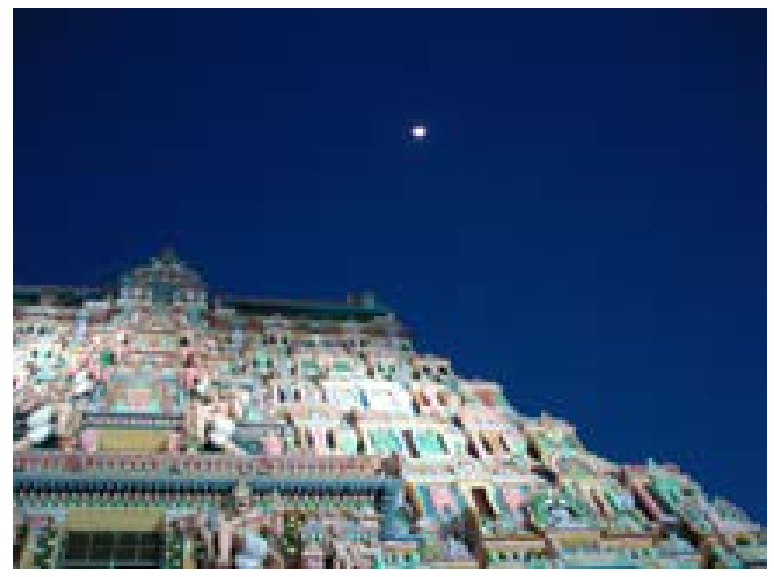

Vista noturna de um dos pórticos de entrada do templo de Chidambaram, Tamil Nadu, Índia.

Fonte: Arquivo pessoal Irani Cippiciani

$\mathrm{Na}$ Índia, a mesma palavra é usada para descrever tanto o teatro quanto a dança, não sendo possível separá-los totalmente, ainda que cada manifestação artística os agregue em proporções diferentes. Para ajudar os artistas na classificação de sua arte, a cultura clássica hindu desenvolveu uma terminologia própria, que norteia e unifica as diversas correntes artísticas por todo o território. São elas: Natya (teatro); Nritta (dança pura) e Nrittya (dança expressiva).

As danças dramáticas indianas absorveram estes conceitos de modo bastante peculiar e se espalharam por toda a Índia, criando diferentes "sabores" para o prato nacional, temperado em cada região de acordo com o gosto das pessoas que lá viviam. Assim nasceram o Bharatanatyam, o Kuchipudi, o Mohiniyattam, o Odissi, o Kathak, o Manipuri, o Sattrya e o Kathakali. Todas as formas de dança dramática que estão em perfeita harmonia com os pressupostos do Natyasastra são consideradas clássicas, independentemente do período histórico de seu surgimento.

Assim, torna-se fundamental conhecer um pouco mais sobre este importante tratado das artes dramáticas. Apresento a seguir uma tradução livre de Irani Cippicaini, dos trechos considerados mais relevantes do primeiro capítulo do Natyasastra sobre suas origens míticas e sagradas:

Após a Idade do Ouro e a Idade da Prata, veio a Idade do Cobre, quando os seres humanos se tornaram vítimas da luxúria e da mesquinharia, engajados em rituais grotescos, oprimidos pelo ciúme e pela desilusão, experimentando igualmente a felicidade e a miséria.

Todas as deidades estabelecidas solicitaram ao grande Deus Brahma a criação de um passatempo que fosse ao mesmo tempo visível, audível e acessível a todo tipo de audiência. Uma forma de entretenimento que pudesse educar e civilizar as classes mais baixas, pois, ao serem excluídas de todo conhecimento e sabedoria, tornavam-se violentas e agressivas. Neste tempo, a sabedoria dos Vedas não era acessível a todas as castas.

Brahma concordou com o pedido e, a partir de informações recolhidas dos quatro Vedas (Rig, Atharva, Sama e Yajur), criou um quinto Veda ao qual chamou Natyaveda.

Brahma disse:

- Esse Veda deverá conduzir aos princípios da verdade e da virtude, da prospe- 
ridade e do sucesso. Deverá conter princípios didáticos e servir de guia para as atividades humanas e suas futuras gerações, demonstrando as várias modalidades teatrais e artesanais. Do Rigveda extrairei o discurso; do Samaveda a música; do Yajurveda a ciência do gesto e da atuação (Abhinaya); e do Atharvaveda, os sentimentos (Rasas).

Então Brahma chamou Bharatamuni e pediu que esse conhecimento fosse transmitido a seres de alma nobre e elevada, que fossem capazes, perspicazes, maduros e infatigáveis. Ouvindo suas palavras, Bharatamuni replicou que os deuses não estavam aptos a obter tal conhecimento porque eram incapazes de receber, conter e compreender a amplitude desse tratado e po-lo em prática. Então Brahma determinou que o próprio Bharatamuni ficasse responsável por essa tarefa.

Assim, ele aprendeu diretamente de Brahma todo o conhecimento contido no Natyaveda e o transmitiu aos seus 100 filhos, dando-lhe a correta aplicação. Sua intenção era ver como os seres humanos podiam ser beneficiados por esse conhecimento e, assim, cada filho engajou-se na tarefa que lhe parecia mais interessante. Bharatamuni concentrou-se nos aspectos principais da encenação teatral: Vrttis (os estilos dramáticos), Sattvati (a concepção mental), Bharathi (o discurso verbal) e Arabathi (o discurso corporal). Brahma sugeriu a ele que acrescentasse um quinto elemento: Kaisiki (charme e graça). E disse: "Para desenvolver Kaisiki necessitamos de Angaharas (gesticulação suave dos membros); Rasa (sentimento corretamente aplicado); Bhavas (estados emocionais claros) e Kriya (atividade física). (Bharatamuni, 1986, cap. I, vs. 45-46, tradução livre).

Após dizer essas palavras, Brahma concluiu que nenhum homem ou mulher no mundo estava apto a desenvolver tal ciência e criou uma classe de seres celestiais capazes de ensinar aos homens tal arte: as Apsaras, bailarinas celestiais e os Ghandharvas, músicos celestiais.

Quando tudo estava devidamente compreendido, chegou a ocasião da performance no grande Festival de Mahendra (a vitória do Deus Indra contra os demônios). No entanto, no dia da apresentação, os Vighnas (espíritos malignos), usando seus poderes, fizeram com que os atores se esquecessem de seus textos e movimentos e ficassem completamente desconfortáveis no palco, gerando grande sentimento de aflição.

Vendo o sofrimento dos atores e percebendo a situação, Indra aniquilou uma série de Vighnas, o que só serviu para aumentar a ira destes contra os atores e a encenação teatral. Não podendo mais suportar aquela situação, Bharatamuni foi até Brahma pedir uma solução para o problema. Então Brahma disse:

- Chame Visvankarmam (o arquiteto celestial) e diga a ele que construa uma casa teatral cercada de todos os preceitos védicos para manter afastados os maus espíritos. Esse teatro deverá ser protegido em todas as suas partes.

Ainda assim, os Vighnas continuavam a perturbar as apresentações. Inquiridos por Brahma, eles disseram:

- Queremos uma forma de arte na qual nós também estejamos representados, com a qual possamos nos identificar. Não gostamos dessas histórias falando só sobre os deuses e os seres celestiais.

Ouvindo tais palavras Brahma determinou:

A arte teatral representará todos os seres presentes em todos os mundos.

Deverá conter referências a sentimentos como piedade, prosperidade, paz, humor, guerra, matança e cenas eróticas.

Deverá conduzir ao caminho da virtude os que trabalharem duro.

Deverá conduzir aos caminhos do amor e civilizar nossa natureza animal, encorajando o autocontrole por meio da disciplina, fazendo forte o fraco.

Deverá trazer luz aos pobres de intelecto e engrandecer as almas nobres, ampliando-lhes a sabedoria.

Esta arte se destinará a todos os seres sem distinção de castas.

Deverá conter imitações de ações, de condutas humanas de diferentes tipos e situações cômicas e trágicas. Nenhum ser deverá se ofender com esse tipo de imitação porque ela é a base da arte dramática nos sete continentes.

Toda peça deverá conter um agente educacional ampliando os aspectos Bhava, Rasa e Kriya. 
Deverá conduzir as pessoas que padecem de aflições mentais à aquisição de uma vida longa e plena por meio do aprendizado da conduta correta.

Deverá conter todos os ramos do conhecimento.

O propósito maior da arte é eliminar o sofrimento causado pelos conflitos próprios da natureza humana.

As pessoas que visitam os teatros não podem ter preconceitos de espécie alguma. Devem possuir elevado senso estético, estando aptos a absorver os conhecimentos transmitidos pela performance.

Estas foram as palavras de Brahma quanto à arte da encenação teatral" (Bharatamuni, 1986, cap. I, tradução livre de Irani Cippiciani).

Não há conhecimento, aprendizado, arte ou habilidade, que sejam ignorados ou omitidos em Natya.

(Bharatamuni, 1986, cap. I, vs. 116, tradução livre de Irani Cippiciani).).

O Natyasastra, grande tratado da arte dramática hindu, escrito em sânscrito, é um dos mais antigos textos sobre a ciência da representação e do gesto na história da humanidade, cujo conteúdo apresenta informações relevantes à compreensão do surgimento e o propósito da arte dramática. Sua Prayoga (práxis) apresenta, em seus mais de trinta capítulos, uma coerência estética, ética e filosófica surpreendentes, sustentada pelos conceitos de Rasa e Bhava, alicerces da arte dramática na Índia. Para confirmar essa prerrogativa apresentamos a própria afirmação de Bharatamuni:

Assim como as pessoas versadas em culinária desfrutam do consumo de várias especiarias que dão sabor aos seus pratos, assim também os homens desfrutam de Bhava por meio da ciência da gesticulação. Por isso, ela recebe o nome de Natya Rasa (Bharatamuni, 1986, cap. 6, vs. 32-33, tradução livre de Irani Cippiciani).).

Acredita-se que o Natyasastra seja resultado de uma compilação de vários escritos produzidos entre os séculos II a.C e II d.C, por diversos pensadores da arte da encenação, representados na figura ancestral e mitológica de Bharatamuni. A palavra Bharata remete ao nome original da Índia. Já a palavra Muni quer dizer sábio, culto. Assim, Bharatamuni, mais do que representar um nome ou um ser histórico, significa "a sabedoria da Terra de Bharata", registrada em um complexo tratado de artes. Tal discussão foi realizada por alguns estudiosos da obra Natyasastra, conforme exemplificado nas citações a seguir.

Idêntica incerteza envolve seu autor, Bharata. Seria inútil procurar por detrás desse nome, que sugere relações simbólicas com algumas divindades, uma individualidade sobre a qual pudéssemos ter um conhecimento histórico. Bharata não é mais que um sábio mítico a quem os deuses ordenaram que criasse o teatro (Scherer, 1996, p. 31).

Há muitos historiadores que afirmam que Bharatamuni é uma figura composta; o Natyasastra com sua coleção de textos emprestados e voltados a uma multiplicidade de diferentes artes e disciplinas, eles argumentam, que não pode ser o resultado do trabalho de um único indivíduo. $\mathrm{O}$ trabalho é resultado, em sua opinião, de uma compilação, como muitos outros textos antigos da Î́ndia (Lath, 2007, p. 127, tradução livre de Irani Cippiciani). 
O Natyasastra, segundo a narração mítica que explica as origens do teatro e seu propósito apresentada acima, também é conhecido como Natyaveda:

Brahma concordou com o pedido e, a partir de informações recolhidas dos quatro Vedas (Rig, Atharva, Sama e Yajur), criou um quinto Veda ao qual chamou Natyaveda. (Bharatamuni, 1986, cap. I, tradução livre de Irani Cippiciani).

A palavra Veda quer dizer conhecimento, mas, mais do que isso, destaca-se por seu caráter sagrado e religioso, visto tratar-se de uma compilação de conhecimentos muito antigos, presentes nos quatro Vedas (escrituras sagradas), escritos por volta de 1.500 a.C. Sendo considerado um texto sagrado, o Natyaveda tornou-se uma referência importante para os artistas indianos, estabelecendo padrões estéticos e filosóficos muito precisos e detalhados, criando toda uma cultura teatral que até os dias de hoje continua viva e coesa aos seus princípios. Esse é o contexto religioso que assegura o florescimento do Natysastra e o legitima. Natya é um veículo para a compreensão da verdade absoluta tão bem expressa nas diversas escrituras sagradas do Hinduísmo. Da experiência estética que ele proporciona nasce um novo ethos social, um novo padrão de homem e uma visão cosmogônica do mundo físico.

A palavra Natya designa, ao mesmo tempo, dança, representação, mímica acompanhada de música ou drama cantado. A palavra Sastra quer dizer tratado, doutrina, regra ou narrativa mítica. Assim, Natyasastra pode ser traduzido por "Tratado da Arte da Representação", sem distinção entre dança e drama, cujo objetivo é representar a vida por meio da recriação de seus elementos, o que implica no desenvolvimento de uma prática que sistematize a criação cênica de modo disciplinado, consciente e estilizado, para atingir os objetivos da arte dramática. E quais seriam tais objetivos? Apresentar, sem juízo de valor, os aspectos atrativos e repulsivos da existência, apostando no discernimento humano para escolher entre uma conduta boa ou má e arcar com as consequências de suas escolhas (o que se relaciona com o conceito hinduísta de Karma). Natya é, ao mesmo tempo, um instrumento moralizante e pedagógico, estabelecendo padrões de conduta e de pensamento considerados mais apropriados para a vida em sociedade e para o florescimento da experiência espiritual.

A audiência reconhece o caráter ficcional de Natya e o intérprete como instrumento, veículo ou portador de uma história que será passada adiante. Não há qualquer intenção de se criar uma ideia de naturalismo teatral e a forma mais evidente de se atestar isso é observar os elevados graus de estilização no corpo do ator e nas soluções cênicas apresentadas. Tudo remete ao caráter supranatural da experiência cênica. A realidade do palco é uma realidade ampliada e transformada, propositalmente, para tocar a esfera do impalpável, do sagrado.

Os oito estilos clássicos de dança dramática, cujos fundamentos encontram-se no Natyasastra, Bharatanatyam, Kuchipudi, Mohiniyattam, Odissi, Kathak, Kathakali, Sattriya e Manipuri recebem, por sua vez, o nome de Natyayoga ou Yoga Artística, sendo considerados um meio de revelação da experiência espiritual através da realidade física, corpórea. Nesta afirmação torna-se evidente o papel da arte dramática como veículo de elaboração dos indivíduos em direção a uma existência mais espiritualizada e conectada com esferas superiores de energia, se assim quisermos 
nomeá-las, divinas.

Após a independência da Índia num levante nacionalista, em meados do século XX, o Natyasastra foi reconhecido como o principal tratado das artes dramáticas hindus e guia de referência para o soerguimento das artes clássicas reprimidas ou solapadas durante o período colonial, como, por exemplo, o Bharatanatyam e o Odissi, tornando-se o responsável por uma unificação das diversas manifestações artísticas presentes em todo seu território, dando-lhes um caráter nacional dentro de sua imensa diversidade regional.

Ainda hoje, o Natyasastra continua a ser um elemento vivo e pulsante dentro da cultura contemporânea da Índia, na qual a palavra Clássico, mais do que remeter a um período histórico, se refere a um ethos, um valor de identidade social e cultural e, por consequência, a um modo de se pensar e produzir arte. Conforme um dos comentadores desta obra:

O Natyasastra, mais do que um manual das artes performáticas ou um tratado estético, se propõe a investigar os pressupostos éticos expressos em suas páginas, o que o torna um coerente texto filosófico (Karnad, 2007, p. ix, tradução livre de Irani Cippiciani).

\section{O Guru Shishya Parampara: a relação mestre-discípulo e as Linhagens}

A Índia é um país onde a tradição oral ocupa um papel de destaque na transmissão de conhecimentos milenares nas mais diversas áreas do saber, mas, especialmente no campo das artes dramáticas, onde a representação viva do conhecimento é uma necessidade premente (Antze, 1995). Nesse contexto, a figura do mestre assume uma importância singular. Ele é, ao mesmo tempo, o esteio moral da tradição e o instrumento de perpetuação de seu ofício, contribuindo para a preservação de diversas manifestações artísticas tradicionais na contemporaneidade.

No entanto, para que a relação mestre-discípulo se estabeleça de modo a dar conta das demandas que se apresentam, torna-se necessário criar também um sistema que regule estas relações e o modo como deverão ser transmitidas para que, ao longo do tempo, seus saberes essenciais não se percam. Assim, nasceu o Guru Shishya Parampara, o sistema de sucessão discipular que há milênios vem norteando as relações entre mestres e discípulos nas mais diversas áreas do saber. A palavra Guru quer dizer 'aquele que dissipa a sobra', a palavra Shishya quer dizer 'discípulo', já a palavra Parampara quer dizer 'Linhagem'.

A Linhagem é a origem, a fonte, o caminho por onde a tradição flui como um rio caudaloso e profundo. Ela representa o esforço humano colaborativo de fazer perdurar no tempo ensinamentos fundamentais para um determinado grupo social, fundamentos que se desdobram em conceitos e práticas muito específicas. E para que esse sistema funcione a contento algo deve ser aceito plenamente, conforme se apresenta neste tradicional Strotam (prece em louvor ao mestre): 
Gurur-Brahma, Gurur-Vishnu Gurur-Devo Maheshwarah.

Guru-sakshat Para-Brahma tasmai Shri Gurave Namah.

O Guru é o Criador, o Guru é o Mantenedor, o Guru é o

Divino Destruidor, o Guru é a Divindade Transcendental,

A este glorioso Mestre, minhas saudações.

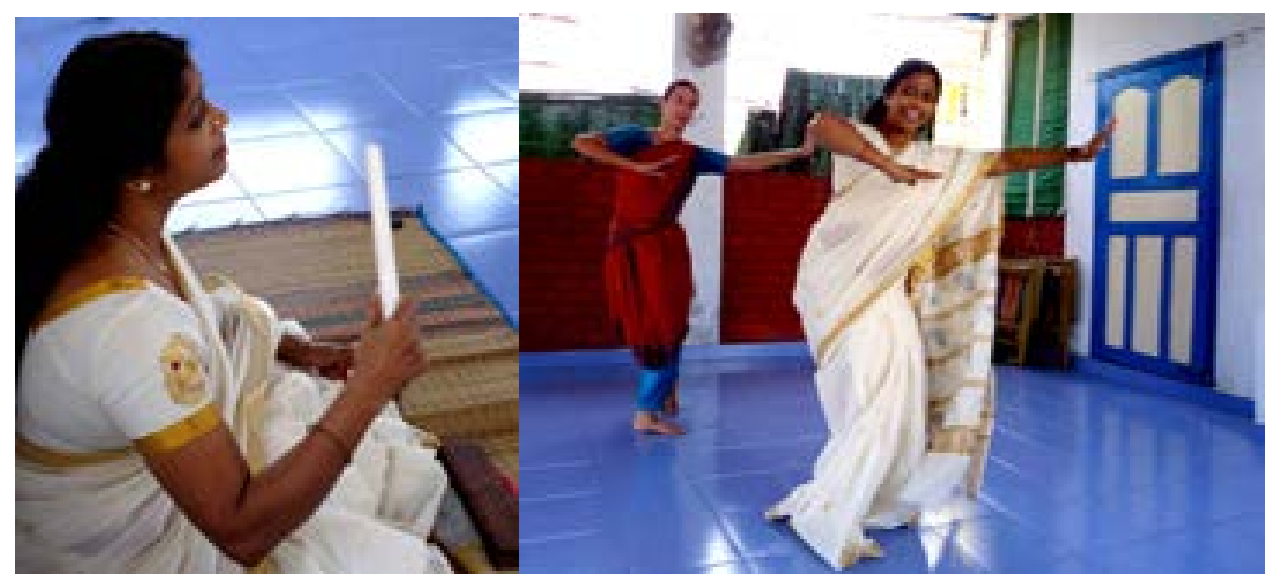

A Guru Maya Vinayan, da Triveni School of Classical Dances em aula de Mohiniyattam com a bailarina Irani Cippiciani. Fonte: Arquivo pessoal de Irani Cippiciani

O Guru é a personificação da divindade, o sagrado materializado na figura de um indivíduo, cujo saber constitui ao mesmo tempo a essência divina e os meios para alcançá-la. O fato de que, na Índia, os mestres sejam representações vivas das divindades indica a necessidade clara de se criar determinados procedimentos de conduta para mediar esta relação com o divino. Tudo se insere de tal modo na rotina de trabalho entre mestres e discípulos que, tais práticas, não são vistas apenas como representações formais de um jogo de poder, mera questão de hierarquia, como, não raro, ouve-se dizer no ocidente.

Nos pequenos rituais diários que se estabelecem entre mestres e discípulos, ao longo de anos de convívio dentro e fora do espaço de aula, começa a surgir um segundo modo de relação que não é determinado apenas pela relação hierárquica, mas por algo bem mais profundo e sólido, uma espécie de vínculo que liga duas almas imortais a um saber que transcende o tempo. Símbolo do conhecimento supremo, o guru tem neste contexto a conexão com o sagrado, tão necessária ao discípulo que deseja ser iniciado neste conhecimento secreto. Tamanha é a força desta estrutura, sustentada pela religião, que sua influência se estendeu para outros países da Ásia, como nos mostra Hanna:

Em grande parte, a importância da dança da Índia assenta no fato de se incrustar na fé hinduísta, predominante na Índia e mantida por uma ampla proporção da população mundial. A Índia, segundo país do mundo em população, tem um legado de dança que se ramifica pelo sudeste asiático, em que grupos locais adaptaram formas da cultura indiana a suas próprias necessidades e a sua estética, e por comunidades do mundo inteiro (Hanna, 1999, p. 151).

A presença dos deuses em toda a base da construção das artes, esta religiosidade premente, permanece no dia-a-dia da Índia, cujas prerrogativas de sagrado e profano não são distintas como no ocidente. 
Embora tudo possa parecer muito abstrato e filosófico, há, na tradição indiana, práticas para externalizar estas concepções. Por exemplo, nas danças dramáticas indianas existe uma prática já bastante assimilada que se chama Namaskaram ou Pedido de Permissão. Trata-se de uma saudação realizada no início e fechamento das aulas, apresentações ou qualquer outra atividade realizada entre mestre e discípulo, que consiste em saudar o Guru tocando seus pés ou suas mãos através de um gestual simbólico codificado e estilizado e, não raro, prostrando-se diante dele.

Cada estilo de dança dramática possui seu próprio Namaskaram, com modos muito peculiares de realizar esta saudação, mas a sutileza deste ato não esta apenas no modo intrincado, belo e simbólico como ele se dá, nem em seu caráter hierarquizante, mas no efeito que ela provoca na psique dos aprendizes ao longo de incansáveis anos de repetição, assim como uma oração bem realizada. Uma verdadeira transformação mental se opera no discípulo que absorve, através deste pequeno gesto diário, conceitos fundamentais a preservação de sua forma de arte: respeito ao mestre e a Linhagem, sem os quais o discípulo nem existiria e o abandono gradativo da ilusão de um 'eu artístico individualizado' pela ideia de um 'eu artístico coletivo', ou seja, os valores da tradição suplantando as vontades individuais.

Há também outras práticas que ritualizam esta relação, sedimentando o terreno fértil onde a experiência espiritual através da realidade corporal, que estas formas de arte objetivam, possa acontecer. Como o Guru Dakshina que é a retribuição material ao Guru, não como forma de pagamento, visto que o conhecimento é sagrado e não tem preço, mas como forma de reconhecimento. O dinheiro, os presentes, ou mesmo os pequenos serviços diários prestados ao mestre, são apenas indicativos desta mesma concepção de mundo.

Alguns também dirão que todos estes procedimentos são, na verdade, um instrumento muito eficaz de apaziguamento do ego, ação necessária à implantação plena e bem-sucedida do projeto de 'eu artístico coletivo', esteio destas tradições durante centenas de anos. Ou, se quisermos utilizar a terminologia hinduísta, a Paramatma ou Alma Suprema sobre a Jeevatma ou Alma Individual, os saberes da tradição incorporados na figura de um mestre acima da necessidade de autoafirmação dos discípulos e ambos como veiculo, a serviço de algo muito maior e mais importante, um conhecimento que flui do centro da divindade.

Este é o cenário onde as danças dramáticas floresceram sob a influência direta e indireta que este modo de relação, este ethos, exerce sobre as práticas e procedimentos artísticos, nos mais diferentes níveis de formação do intérprete. O sagrado é uma experiência múltipla, mas depende de algumas condições elementares para manifestar-se, o Guru Shishya Parampara é um caminho seguro e bem testado que a tradição oriental nos oferece, não como modelo a ser copiado indiscriminadamente, mas como uma possibilidade a ser considerada. 


\section{O sagrado na geometria do Bharatanatyam}

\section{O contexto histórico-religioso onde a dança floresce}

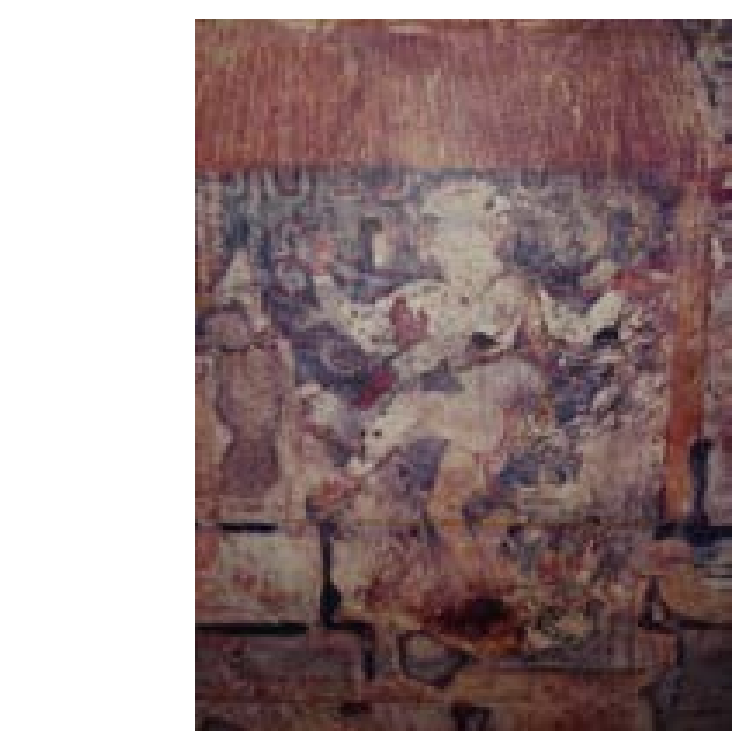

Imagem tradicional do Deus Shiva Nataraja, Dinastia Chola, sec. III-IV a XII. Fonte: Arquivo pessoal de Irani Cippiciani

O Bharatanatyam nasceu no estado de Tamil Nadu, no sul da Índia. Encontramos as primeiras referências ao estilo na literatura tâmil dos séculos II a.C a V d.C. No entanto, até meados do século XII, ele era conhecido como Dasiattam ou Sadirattam. Dasi, quer dizer Servo, de onde também deriva a palavra Devadasi (serva de deus), designação dada às dançarinas que viviam nos templos e Attam, quer dizer dança e/ ou drama. Assim, Dasiattam poderia ser traduzida por 'Dança-Drama Devocional', por ser executada dentro dos templos, associada aos rituais religiosos.

Outro importante fator para a consolidação do estilo foram os Bhagwata Mela Natakams, dançarinos que interpretavam passagens dos textos sagrados hindus fora dos templos, se valendo de uma estrutura cênica que variava entre demonstrações de virtuosismo técnico e de dança-dramática.

O Dasiattam, por sua vez, era uma dança executada somente por mulheres provenientes das castas mais baixas e tida como auspiciosa. A transmissão de conhecimento era familiar e passava de mãe para filha. Era dito que as Devadasis tinham a sorte suprema porque, sendo esposas de Deus, nunca ficavam viúvas. Os homens não eram estimulados a dançar nos templos, como sinal de mau agouro. Apesar disso, os Kuttar, realizavam danças rituais fora dos templos.

Entre os séculos X e XIV d.C., as Devadasis receberam apoio da Dinastia Chola Rajaraja I, especialmente nos templos de Brihadeswara, Tanjavur, Gangasikonda, Meenakshi Swaram em Cholapuram, Meenakshi Aman em Madurai e Nataraja em Chidambaram. Este período corresponde tanto a sedimentação do estilo, quanto ao seu apogeu, com centenas de Devadasis realizando seu serviço devocional nos templos.

Posteriormente, surgiram as Rajadasis, ou bailarinas da corte, que dançavam para o divertimento de seus patronos. Nesta época, o Bharatanatyam recebe influên- 
cias muçulmanas e passa a se chamar Sadirattam. Porém, de modo geral a estrutura da dança é preservada.

Durante os anos de colonização, muitas Devadasis, expulsas de seus templos, foram para as cortes e se tornaram Rajadasis ou passaram a dançar em festividades, recebendo o nome de Alankaradasis ou dançarinas populares. A tradição das Devadasis se manteve viva até o começo do século $X X$, quando o governo inglês baniu definitivamente a prática do Sistema Devadasi nos templos, associando sua prática à prostituição.

Em 1931, surgiu em Madras, capital de Tamil Nadu, hoje conhecida como Chennai, um movimento de resistência contra a proibição inglesa que permitiu o ressurgimento do estilo depois de anos de preconceito e esquecimento. Foi neste período que a dança recebeu o nome de Bharatanatyam, em homenagem ao sábio Bharata, que havia escrito o Natyasastra, o grande tratado das artes para o povo hindu.

Rukmini Devi Arundale e Krishna lyer foram os grandes responsáveis pela formalização e reestruturação do estilo. Rukmini começou a dançar apenas aos 30 anos de idade e foi a primeira mulher brâmane a fazê-lo. Foi ela também quem fundou a Kalakshetra Foundation para difusão das formas de arte clássicas do sul da Índia, prioritariamente o Bharatanatyam. Atualmente, a Kalakshetra é um dos mais importantes centros de formação nas formas de arte clássicas da Índia (dança, música, teatro e canto).

Desde então, a dança veio, gradativamente, dissociando-se do sistema das Devadasis. O motivo é que, pela primeira vez na história, a dança saía das castas mais baixas e migrava para as castas mais altas. Isso também exigiu um grande esforço de adequação e sistematização do processo de formação e treinamento dos bailarinos e a fixação de um repertório específico para um programa completo de Bharatanatyam. Foi neste contexto e graças ao célebre Quarteto Tanjore (os irmãos Chinniyah, Punniah, Vadivelu e Shivanandam), na Madras Music Academy, que se formalizou o repertório do estilo como o conhecemos hoje.

O Bharatanatyam que se pratica no século XXI é resultado deste longo processo histórico, político e religioso e, contudo, não está restrito a ele. Frente as demandas que se apresentam, o Bharatanatyam tem assumido diferentes facetas e contornos em toda a Índia, que representam o esforço consciente de seus praticantes em mantê-lo vivo e conectado ao seu tempo. A dança já não é mais realizada unicamente dentro dos templos, assumindo seu caráter teatral e espetacular. No entanto, as prerrogativas religiosas que a fundamentam, continuam a existir na temática apresentada e na relação ritual que seus praticantes mantêm com seu ofício. Como uma vez me foi dito pela Guru Kalamandalam Sumathi, da Natyalaya School of Classical Dances, de Perumbavoor, Kerala: 'A devoção não precisa ser vista, mas se ela existir no coração do bailarino, a dança será mais bela'.

\section{Treinamento e repertório do estilo: o corpo como veículo do sagrado}

O Bharatanatyam é um estilo marcado pela geometria, pela precisão das linhas e ângulos que o corpo desenha no espaço, criando formas esculturais perfeitas. Sua tônica é a simetria aliada à velocidade, equilibrando cada parte do corpo num jogo dinâmico de poses que se sucedem. Acredita-se que esta dança foi ensinada aos homens 
pelo próprio deus Shiva Nataraja, o rei de todos os dançarinos, aquele que domina o tempo (Kala) e o ritmo (Tala). Os movimentos do Bharatanatyam são lineares e sua tônica é, ao mesmo tempo, grave e serena, numa tentativa de equilibrar as energias Tandava (masculina, representada pelo lado direito do corpo) e Lasya (feminina, representada pelo lado esquerdo do corpo), conforme podemos observar na figura andrógina de Shiva Ardhaneshwara. É do jogo infinito destas duas qualidades de energia Shiva (estático) e Shakti (dinâmico), que nascem os movimentos de cada parte do corpo, dos grupos de exercícios que configuram a técnica e, finalmente, as coreografias.

No Bharatanatyam, o corpo é dividido em dois triângulos principais: dos ombros ao quadril e do quadril aos pés, e os movimentos corporais são construídos a partir do diálogo entre estes triângulos com o objetivo de gerar novos triângulos secundários, novas linhas perfeitamente alinhadas. A postura base é o tradicional Aramandi (como a primeira posição do ballet clássico), posição comum a quase todas as danças indianas. Esta postura cria um jogo de tensão entre a parte superior do corpo que permanece mais relaxada e a parte inferior que assume a responsabilidade de sustentar o corpo. A energia Tandava/Shiva permanece na base, dando sustentação a construção corporal e a energia Lasya/Shakti na metade superior do corpo, que fica livre para desenhar no espaço as geometrias tão características do estilo.

A flexão de pernas, com os joelhos bem abertos e os pés espalmados no chão, ao contrário do ballet, impulsionam o corpo do bailarino para o chão, em direção a Mãe Terra. Todas as danças indianas possuem esta relação intrínseca com a Terra, como entidade viva. A postura da dança, o bater os pés no chão e dançar descalço são alguns reflexos desta atitude respeitosa. O pedido de permissão do Bharatanatyam, ou Namaskaram, contempla uma saudação à Terra dizendo:

Samudra Vasane Devi Parvata Stana Mandale

Naatyam Karishye Bhoodevi Paadasparsham Kssamasva Me

Ó Devi, cujo oceano é a vestimenta e as montanhas, o seio

Por favor, perdoe-me por dançar sobre você com meus pés

Então o bailarino se agacha e toca o chão levando as mãos aos olhos (pedindo para que a Terra lhe traga o conhecimento pela via da razão) e depois o coração (pedindo para que a Terra lhe traga o conhecimento pela via da emoção). Ele então se levanta e faz o tradicional gesto de saudação com as mãos unidas no centro do peito e uma suave inclinação do tronco para frente em atitude solene. Esta ação será repetida durante todos os dias, todos os anos de prática do estilo, seja no espaço de ensaio, seja nas apresentações, como um mantra corporal, cuja a repetição faz nascer no coração do bailarino um sentimento de devoção primevo, tão necessário à a sedimentação de um estado de consciência mais sutil, tão essencial para a dança indiana e a cultura hindu como um todo. O mesmo que Grotowski nos aponta em sua proposta da Arte como Veículo:

Quando falo da imagem do elevador primordial e da arte como veículo, me refiro à verticalidade. Verticalidade - o fenômeno é de ordem energética: energias pesadas, mais orgânicas (ligadas às forças da vida, aos instintos, à sensualidade) e outras energias, mais sutis. A questão da verticalidade significa passar de um nível assim chamado grosseiro - em certo sentido poderíamos dizer "cotidiano" 
para um nível energético mais sutil ou mesmo em direção a higher connection [...]. Aqui, há também uma outra passagem: que se aproxima da higher connection - isto é, em termos energéticos, que se aproxima da energia muito mais sutil - coloca-se também a questão de descer trazendo de novo essa coisa sutil dentro da realidade mais comum, ligada a "densidade" do corpo (Grotowski, 1959-69, apud Raulino, 2001, p. 235).

O Namaskaram (pedido de permissão), assim como outras ações rituais realizadas no espaço de aula-treinamento entre mestres e seus discípulos ao longo de anos de interação, são o instrumental para realizar esta 'passagem energética' de que nos fala Grotowski, tão fundamental à experiência estética. Esta pratica oriental milenar reaparece com força no cenário contemporâneo ocidental, instigando e estimulando profundamente os artistas a elaborarem, por sua conta e risco, sem o amparo de uma tradição estruturada, os caminhos que os conduzirão a tal experiência espiritual através da arte, uma vez que, embora os exemplos orientais sejam uma referência fundamental, sua mera transposição para um contexto contemporâneo não os tornam, por si sós, capazes de produzir o resultado que se vê dentro do escopo das tradições orientais. De Stanislavsky, Artaud, Brecht até artistas contemporâneos como Barba, Brook, Mouchkine, entre tantos outros, o Oriente continua a ser uma fonte de inspiração, uma referência para a criação de novos paradigmas artísticos e proposições estéticas para a cena contemporânea.

O repertório de movimentos do Bharatanatyam é dividido em grupos de Adavus (exercícios). Cada grupo de Adavu se encarrega de desenvolver uma habilidade específica que, ao longo do tempo, estrutura o corpo do praticante dentro das prerrogativas do estilo. É uma construção minuciosa, elaborada, onde há pouco espaço para a improvisação, num primeiro momento. É preciso dominar a técnica completamente, para então, não tendo mais que se preocupar com ela, chegar a outras esferas de criação artística, onde haverá, sim, muito espaço para a criação e reelaboração dos cânones da tradição.

É como se tudo na tradição hindu, do âmbito mais casual ao mais elaborado, seguisse o mesmo princípio ritual cíclico que faz do 'Princípio da Repetição', que não passa duas vezes pelo mesmo lugar, um método de experiência espiritual, de transformação dos sujeitos, extremamente eficaz. Cada Adavu deve ser executado em, pelo menos, 3 velocidades distintas em modo ascendente e descendente.

Idealmente, o praticante fará um grupo de Adavus na sequência, em progressão rítmica constante: ascende-descende-ascende sucessivamente. $O$ efeito desta ação contínua sobre o artista, ao longo de anos de treinamento, não é apenas de condicionamento físico e mecanização de movimentos, o que seria o esperado. A longo prazo, esta repetição ritmada e metódica, que conclama à vida cada músculo, cada veia do bailarino, tem o poder de romper a dicotomia corpo-mente atingindo o estado mental necessário às experiências espirituais mais profundas, como bem destaca o teórico indiano Jhanji:

O Rasika e o Yogin, ambos, estão livres do aprisionamento do ego. Enquanto o Rasika atinge essa liberdade por meio da experiência estética, o Yogin a atinge suplantando a identificação com seu corpo físico e unificando sua mente à consciência universal. Apesar de trilharem caminhos diferentes, o objetivo de ambos 
é o mesmo - a autorrealização de sua essência natural em seu aspecto perene e imperturbável (Jhanji, 2007, p. 97, tradução livre de Irani Cippiciani).).

Pensar a técnica é, portanto, criar o instrumental que torna possível esta qualidade de experiência com o divino, o sagrado, algo muito mais complexo do que a memorização de sequências corporais, gestos de mão e expressões faciais codificadas. Muitos artistas ocidentais, intuem o poder desta estrutura e buscam aproximarem-se dela, mas, não raro, limitam-se apenas a apreensão da forma externa, seja em favor de seus treinamentos ou espetáculos. Isso se explica, em parte, pelo peso que a palavra 'devocional' assumiu no ocidente e a associação, sempre duvidosa, entre religião e arte vista com muita ressalva por aqui e em parte por que não há, na maioria dos adeptos ocidentais, o ímpeto de se dedicar à estas formas de arte pelo tempo necessário para que, de fato, as transformações profundas que elas suscitam possam se operar. O tempo no oriente é um tempo cósmico, não pragmático ou dividido em módulos de aprendizado. A prática da dança indiana é, dentro desta perspectiva, a escolha de um caminho espiritual que se revela através da experiência estética, como bem nos apresenta o filósofo indiano Coomaraswamy:

Assim como o Amor é a realidade vivenciada pelo Amante, e a Verdade é a realidade vivenciada pelo Filósofo, a Beleza é a realidade vivenciada pelo Artista: e todas elas são fases do Absoluto (Coomaraswamy, 1985, p. 36, tradução livre de Irani Cippiciani).

O Bharatanatyam tem, em média, 15 diferentes grupos de Adavus, num crescente técnico. Esse número pode variar a depender da Linhagem (Parampara): Thanjavur, Kalakshetra, Pandanallur ou Vazhoor. Cada grupo pode também apresentar pequenas variações de execução dentro de cada Linhagem ou Escola. Uma Linhagem é o resultado de centenas de anos de dedicação e do esforço de inúmeros artistas, a um modo distinto de pensar o Bharatanatyam. Todas elas seguem as diretrizes expressas no Natyasastra, mas com pequenas diferenças estilísticas que acabam por configurar diferentes 'sotaques' para o estilo. O mais importante em todos eles, no entanto, é que o caráter espiritual da prática da dança esteja preservado sobre qualquer diferença estilística que possa existir.
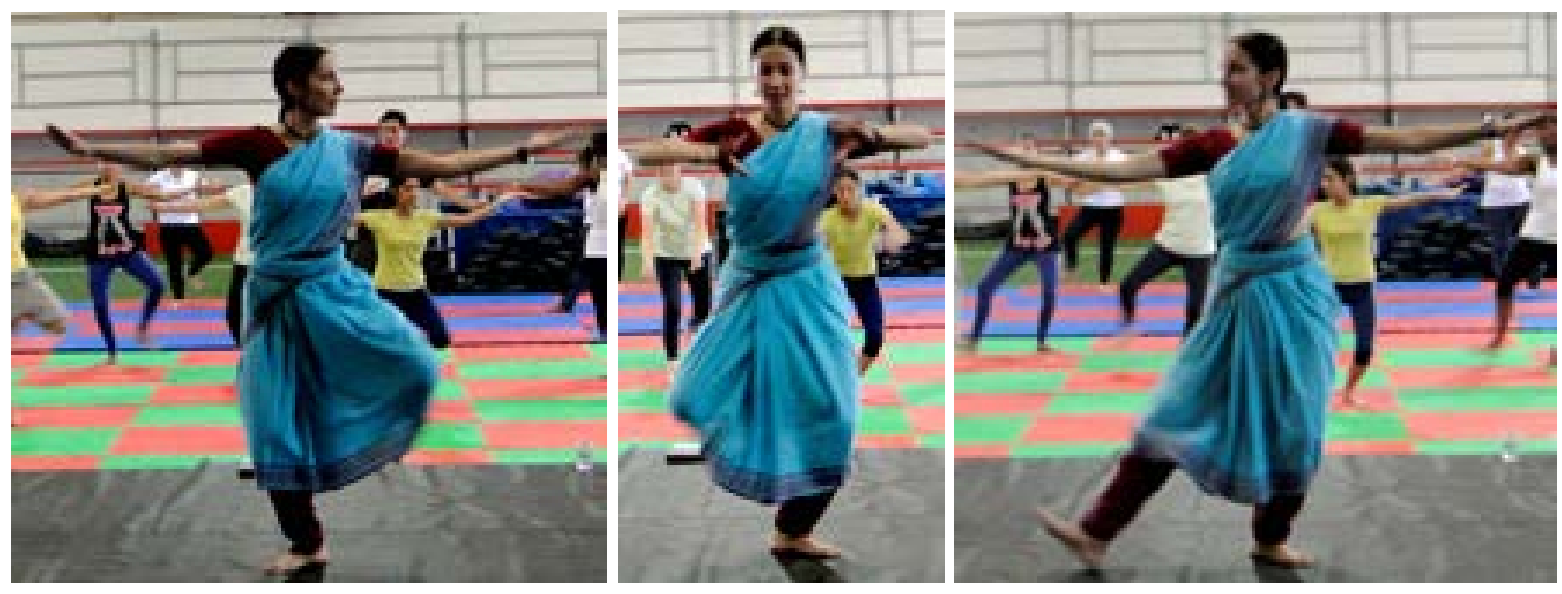

Exemplos de movimentos corporais que formam os Adavus no estilo Bharatanatyam Fonte: arquivo pessoal Irani Cippiciani 
Todas as Linhagens, no entanto, seguem a mesma estrutura dramática, cujo propósito é atingir as Purusarthas ou quatro metas da existência humana: Kama (prazeres sensoriais), Artha (prosperidade), Dharma (conduta moral) e Moksha (liberação espiritual). Os itens coreográficos que compõem um programa tradicional de Bharatanatyam são: Vandanam (oração a um deus), de onde derivam muitas variedades de itens invocatórios, como os Pushpanjalis, Mallaris, Todayams e Kavuthuvams, todos têm, em comum, o caráter de oração pedindo para que determinada divindade abençoe a apresentação, o artista e a audiência.

Segue-se então o Allaripu, que quer dizer 'flor em botão'. Trata-se do primeiro item essencialmente técnico do programa e sua metáfora é bastante significativa para os praticantes 'a bailarina é uma flor em botão', guardando todo potencial desta condição. Então temos o Jatiswaram, item abstrato com grau de sofisticação e elaboração maior que o Alarippu. Nele, além do elemento rítmico ou Jati, introduz-se o elemento melódico ou Swaram. Na sequência vemos o Sabdam onde aparecem os primeiros esboços do Abhinaya ou elemento expressivo tão característico das danças indianas ainda num estágio muito elementar. Ele é o prenúncio do Varnam, item central do repertório do estilo, onde expressão e técnica aparecem de modo extremamente balanceado. São itens muito longos e complexos que revelam a maturidade do artista, seu grau de refinamento e domínio da técnica. Alguns dizem que o Varnam é a alma e o corpo do Bharatanatyam.

Até aqui construiu-se a curva ascendente do espetáculo, segue-se então os itens essencialmente expressivos, os Padams, abrindo a segunda metade do programa numa curva descendente que traz o espectador de volta para seu centro. Existem muitas qualidades de Padams ou danças que contam histórias: Padyams, Keerthanas (devocionais), Javalis (valorizam o aspecto Sringaram ou sentimento erótico), os $\mathrm{Pa}$ dams (temas da vida cotidiana) e os Ashtapadis (histórias de amor, especialmente as que envolvem Krishna, extraídas do Gita Govinda de Jayadeva). Cada um deles possui uma estrutura de construção sutilmente diferente, mas seu objetivo é vivenciar a experiência emocional que a arte proporciona.

A teoria estética hindu possui uma terminologia própria para designar essa experiência, os conceitos de Rasa que é a experiência estética que se saboreia e Bhava que é o manancial de emoções onde o artista se debruça para a criação. Trata-se de conceitos e ideias muitos complexas que reverberam na construção dos itens expressivos através de inúmeros exercícios que fazem aflorar a capacidade expressiva dos intérpretes. Este treinamento exige um grau de maturidade muito grande do praticante e não pode acontecer antes que este tenha atingido certo grau de maturidade técnica e emocional.

Por fim, vemos o Thillana, influência árabe no programa tradicional, item vibrante, impactante, com poses esculturais, sequências intrincadas de dança abstrata e um Slokam (hino laudatório) final em louvor a alguma divindade. Este item tem a função de fechar o programa e reestabelece a curva ascendente, o mesmo padrão que já constatamos no treinamento dos Adavus: ascende, descende e torna a ascender. Essa ascensão final anuncia Moksha, o enlevo e a liberação espiritual que deve acompanhar tanto o artista, quanto a audiência ao final do espetáculo, após a apresentação do item de encerramento, o Mangalam, que quer dizer auspicioso. Uma 
despedida desejando que a prosperidade, a felicidade e a bem-aventurança esteja em tudo e em todos. Um programa completo de Bharatanatyam dura, em média 2 horas, e é uma experiência densa onde o sagrado se coloca, firme e gentilmente, dentro da experiência mundana.

Dentro desta perspectiva, não podemos esquecer o valor simbólico que as vestimentas, ornamentos e maquiagens ocupam neste tipo de arte ritual. $O$ bailarino, sendo veículo de deus, deve vestir-se e maquiar-se a altura desta responsabilidade. Ele é a ponte entre o homem e o sagrado, o veículo de comunicação entre céu e terra, um mensageiro que anuncia, num jogo de revelar e esconder, a presença do divino que habita em cada um de nós.

\section{Mitologia e religião na construção do estilo Odissi}

\section{Origens das tradições Mahari e Gotipua}

Existem várias interpretações sobre a origem dos Gotipuas, meninos entre 6 e 16 anos que dançam vestidos de mulher na tradição de Odhisa. Com certeza o aparecimento de registros sobre eles, datam do século $\mathrm{XV}$, decorrentes das invasões $\mathrm{Mu}$ ghal (séc. XVI ao XVIII) neste estado, período de grande desenvolvimento econômico e cultural, em que as Maharis, dançarinas sagradas se dedicavam aos serviços dos templos. A partir do século IX, no entanto, já encontramos registros de sua presença nos principais templos do estado de Odhisa. As Maharis levavam uma vida casta e tinham uma grande projeção social. Eram, de qualquer forma, consideradas 'princesas' que se tornaram Maharis (Massey, 1989) Tiveram aí seu apogeu de respeito e credibilidade, possuindo vilas e todo seu sustento com os trabalhos sagrados dos cultos aos deuses nos templos até as invasões mulçumanas.

A versão mais corrente considera que os Gotipuas (Goti - simples, Pua - menino) apareceram para que a dança, forma principal de culto aos deuses, pudesse ser apresentada nas festas públicas, uma vez que as Maharis não podiam se apresentar fora dos templos ou se tornariam impuras.

Portanto, os Gotipuas foram criados para realizar as festas e celebrações de fora do templo e substituindo as Maharis, como é explicado nas seguintes linhas: Por ordem dos Reis Gabana (isto é, governantes Mughal) bailarinos devem ser enviados porque as dançarinas perderiam sua religiosidade (Gauhar, 2007, p. 71).

Outra interpretação, associada a filosofia Vaishnava, afirma que todos os devotos são almas, no conceito Shakti-Bhava, no qual a devoção ao Sr. Krishna deve ser expressa como o amor das Gopis (pastoras) por ele. O Sr. Krishna está intimamente associado a vaca e ao pastoreio, e metaforicamente às Gopis, suas devotas, que dançam ao seu redor simbolizando todas as almas. Diante de Deus todos somos mulheres, todos somos Gopis, "pastoras" (as amantes de Krishna), porque o pastoreio na Índia, atividade feminina, tem por objetivo o leite e não a carne. Em outras palavras, os seres humanos são como as Gopis, e a expressão de sua devoção deve se manifestar como o amor delas por Krishna. Desta forma, os meninos estariam representando as Gopis, mas nunca estiveram dentro dos templos (Gauhar, 2007). 
Estando e acontecendo nas ruas, em festividades que estendiam para fora do ritual templário as energias do sagrado, as danças dos Gotipuas absorveram várias influências até se tornarem excessivamente acrobáticas, porém não perderam os princípios básicos da dança de Odhisa: o Odissi. Há uma menção sobre esta dança no Natyasastra, considerado o quinto Veda, ou seja, o quinto livro da sabedoria - que trata das Artes Cênicas - quando cita Odra Maghadi como um dos estilos regionais de dança na Índia.

Estudos históricos mais profundos ainda estão por serem feitos sobre a origem dos Gotipuas, mas sabemos que o território onde hoje está o estado de Odhisa foi invadido várias vezes, e orgulha-se de ser a síntese cultural de origens diversas, que contribuíram para a construção de elementos culturais da atualidade, e que há formas congêneres em outros estados do sul da Índia que podem ter a mesma origem ou terem sido influenciadas pela cultura deste. A posição geográfica central leste propiciou ondas de influências que culminaram com uma filosofia muito original: 0 Dharma ou Fé em Jagannatha. Como em outras partes da Índia, a filosofia religiosa está na base das estruturas artísticas e a dança está embrenhada neste complexo, no qual permanece até hoje.

Observando a história de Odhisa, imagens da dança e dançarinas rituais acompanhadas de músicos aparecem desde o século II a.C. em cavernas, período do reinado de Kharavela, época de grande desenvolvimento das artes. As imagens possuem grande semelhança com os movimentos atuais do Odissi e das estatuárias dos templos de Odhisa, mas acreditamos que, além do forte entroncamento com a religião, o sistema de castas foi um fator importante de contribuição de resistência nas tradições indianas. O período de II a IX d.C. foi bem conturbado, com instabilidades políticas recebendo influências do Budismo, Jainismo, Tantrismo e outras filosofias, culminando com a Filosofia Vedanta, mas mantendo as raízes culturais, assimilando as informações e transformando-as. Podemos observar, por exemplo, que a filosofia da transsexualidade divina tem origem bem antiga, e “... Em vários momentos da História de Odhisa, homens de diferentes raças e fé religiosa exerceram influências e contribuíram para a assimilação de várias ideias, pensamentos e crenças", como diz Samson (1987, p. 95).

Ao longo de textos Hindus e Filosofia Védica há muitas descrições de santos, semideuses, e até mesmo o Senhor Supremo que transcendem as normas de gênero e manifestando várias combinações de sexo e gênero. Estes incluem fêmea, macho, hermafroditas e todas as outras possibilidades. No Hinduísmo, Deus é reconhecido como ilimitado e não atado por quaisquer restrições de gênero. Para efeitos de desfrutar de passatempos transcendentais (Lila), o Senhor Supremo manifesta inúmeros tipos e formas, como um ator em um palco.

Como partes integrantes do Senhor Supremo, as entidades vivas diversas também podem ser vistas para se manifestar dentro de todo o espectro de possibilidades sexuais e de gênero. Do ponto de vista impessoal, a alma não é masculina, feminina ou hermafrodita, mas parte da potencialidade pessoal. Neste sentido as observações de Banerji podem esclarecer a potência da tradição Gotipua como forma de união entre o sagrado e o profano, presente em todas as linguagens artísticas na Índia: $O$ coerente tecido da vida indiana nunca foi arrendado pela dicotomia ocidental de 
crença religiosa e prática mundana. Na dança, particularmente, o que reforça esta hipótese é presença intrínseca da mitologia na dança interpretativa (Abhinaya) cujo conteúdo é a própria cosmologia que se concretiza de forma expressiva nas encarnações dos deuses, na cosmogonia e na poesia, principalmente no Gita Govinda do poeta Jayadeva (séc. XII d.C.) que narra as relações amorosas de Krishna e Radha que exerceu influência no renascimento de todos os estilos de dança após a Independência: "Esta confluência gera a dança como metonímica, uma parte do todo na vida", (Hanna, 1999, p. 153).

Outro ponto importante para as danças dramáticas indianas, em especial o estilo Odissi, é a não separação dos aspectos eróticos da Mitologia e da Religião, priorizando uma visão não fragmentada da experiência espiritual que engloba, em si, aspectos sexuais, como bem nos salienta Hanna:

O sagrado e o secular, o ritual e o divertido, o espiritual e o sexual não tem em toda parte o caráter dicotômico, tão comuns nas sociedades pós-industriais, especialmente as cristãs. Ao passo que o cristianismo separe o sagrado e o sexual (ainda que use a metáfora sexual "paixão pelo amor de Deus"), um componente comum no hinduísmo funde divindade e erotismo numa feliz união (Op. Cit., 1999, p. 151).

Esta sexualidade e erotismo sublimados aparecem no poema Gita Govinda, de Jayadeva, que possui grande importância no repertório expressivo do estilo Odissi. Gita Govinda significa A Canção de Krishna, o senhor do rebanho e das Gopis (as pastoras leiteiras); poema dedicado pelo poeta a Krishna, sétima encarnação de Vishnu, (deus de sua devoção) e sua amada, Radha, a Gopi preferida. Esta obra-prima foi também utilizada na construção de outros estilos clássicos em toda a Índia, musicando, cantando e encenando as relações amorosas entre Krishna e Radha.

Dedicado à sua esposa, logo no primeiro verso o poeta Jayadeva se autodenomina o submisso amante de Padmavati (Sarva Lakshmi May), Mahari no templo de Lord Jagannatha em Puri, declarando que seu coração é a morada que transborda a poesia do Lila (o Jogo) e de Rati Keli (o amor apaixonado) dos encontros entre Krishna e Radha.

Por volta do século XVI de nossa era, sob domínio Mughal, foram criadas as Akhadas (Gymnasiums) por Ramachandradeva com o objetivo de treinamento militar, mas que eram muito próximas ao conceito ocidental de Club com atividades culturais, e que abrigaram os Gotipuas. Vindo daí a ênfase no Bandha Nritya - movimentos acrobáticos, que são a principal característica deste estilo atualmente, mas que neste momento eram apenas um item do treinamento, e que não era executado pelas Maharis, cuja dança primava pela qualidade lasya (suavidade). O que vale a pena esclarecer é que não havia, como ainda hoje não há, separação clara entre sagrado e profano nos moldes ocidentais na Índia. O termo Mahari significa "aquela profundamente apaixonada por Deus (Lord Jagannatha)" enquanto os Gotipuas seriam as almas devotas. A reclusão das Maharis tem mais ligação com o advento do patriarcado e o domínio do espaço público advindo das várias invasões, no sentido de protege-las, e garantir sua pureza.

As invasões mulçumanas posteriores trouxeram a decadência cultural, a des- 
truição dos templos e das tradições Mahari e Gotipuas, que continuaram a existir sem a força e importância dos períodos anteriores, que contribuíram para a preservação dos princípios básicos da dança Odissi. Os principais gurus responsáveis pelo renascimento deste estilo, foram Gotipuas, porque esta tradição migrou das rotas mercantis para os vilarejos menores, e com isso conseguiu sobreviver com mais intensidade que a tradição Mahari que estavam ligadas aos grandes templos nas cidades. Ainda assim, algumas remanescentes desta tradição estiveram presentes no processo de recuperação da dança, mas estão extintas. O Guru Pankaj Charan Das, por exemplo, filho de Mahari, foi Gotipua e seu estilo foi marcado pela delicadeza presente em seu estilo técnico e suas coreografias. Desta forma, as duas características da dança, segundo o Natyasastra: Tandava (másculo, viril) e Lasya (delicada, suave, feminina) foram concretizadas no estilo Odissi, através dos Gotipuas e das Maharis.

\section{Estética e Treinamento}

A forma atual do Odissi é o resultado de trabalho de sábios Gurus, e destacamos aqui Pankaj Charan Das, Kelucharan Mohapatra, Mahadeb Rout e Debaprasad Das, como os pioneiros. Os princípios são os do Bharatanatyam descritos acima, sendo que os aspectos Tandava e Lasya vieram da tradição Gotipua e Mahari, respectivamente. Neste período, viviam as últimas Maharis: Hariprya Devi, Kokilaprava Devi e Laxmipriya Mohapatra, que auxiliaram a pesquisa que incluiu as esculturas do Templo do Sol em Konark. A estética do Odissi tem a particularidade do movimento do tronco, único entre os estilos clássicos, o que produz uma sensualidade e suavidade singulares. Tanto o treinamento como as apresentações seguem o ritual de abertura semelhante ao descrito no Bharatanatyam, depois do canto do Mantra:

$\begin{array}{lcr}\begin{array}{l}\text { Angikam } \\ \text { Vachikam }\end{array} & \begin{array}{c}\text { Bhuvanam } \\ \text { Sarva }\end{array} \text { Chandra } & \begin{array}{r}\text { Yasya } \\ \text { Ahangayam } \\ \text { Taradi }\end{array} \\ \text { Tam Numah Satvikam Shivam. } & & \\ & \\ \text { Nós nos curvamos a Ele o Uno benevolente cujos membros são do mundo, cuja } \\ \text { canção e poesia são a essência de toda língua, cujo traje é a lua e as estrelas ... }\end{array}$

Seguido do Strotam dedicado ao Guru como personificação das divindades Brahma, Vishnu e Shiva, já apresentado anteriormente.

O treinamento começa com 10 exercícios selecionados pelo Guru, dentre os muitos existentes. Estes são posturas do Yoga executados dinamicamente em 3 ou 4 ritmos: lento, médio, rápido e muito rápido. Esta dinâmica será a de todos os exercícios inclusive Chowk e Tribang. Os pontos de partida são as 26 posições dos pés (Paada), 10 movimentos de pernas (Paada Sanchara), 4 movimentos de tronco, 8 movimentos de olhos mais 20 exercícios de expressão, 9 movimentos de cabeça, 4 movimentos de pescoço, 28 hastas mudras (gestos codificados das mãos) simples e 23 duplos, executados com as duas mãos (Mohanty, s/d).

No Odissi as sequências de treino técnico têm duas instâncias: 10 Chowk e 10 Tribang, que correspondem a Tandava e Lasya, ou seja, masculino e feminino. A mo- 
vimentação de Chowk tem o quadrado como base e movimentação bidimensional a princípio, enquanto o Tribang tem como base o triângulo e base tridimensional. Evidentemente, há uma curvatura nestes conceitos na execução dos exercícios sem radicalismo no bidimensional e tridimensional porque a dança é tridimensional. Além disso, tem exercícios Charis e Bramaris (caminhadas e giros). Depois disso, passa-se para as coreografias de repertório. Um espetáculo de Odissi tradicionalmente possui - Mangalacharan: peça de abertura em que se saúda a Mãe-Terra pedindo-se permissão para dançar, quando se oferece flores a Lord Jagannatha, imagem que está no altar. A maioria das coreografias deste item são dedicadas a Lord Ganesha, o Removedor de Obstáculos; ele aparece sempre mesmo quando o Mangacharam é dedicado a outros deuses.

Segue-se a dança pura, Pallavi - que significa bem elaborado, e é o espaço do dançarino exibir suas habilidades técnicas, o Abhinaya - dança dramática e concluise com o Moksha - a Liberação, que também é uma dança pura. As coreografias têm uma ordem de aprendizado de acordo com a complexidade dos movimentos.

\section{Considerações Finais}

Este artigo abordou alguns aspectos teóricos, filosóficos, pedagógicos e metodológicos das danças clássicas indianas tendo como elemento agregador a materialidade dos aspectos sagrados, presentes na Tradição, tanto nas relações entre os artistas e seus modos de relacionamento, quanto em suas práticas. O objetivo deste trabalho é oferecer subsídios ao leitor para compreender, de modo mais profundo, a íntima relação que há entre o universo da religião, filosofia e mitologia hindus e a criação artística em dança, especificamente.

No entanto, cabe lembrar que todas as formas de arte da Índia, por diferentes meios e técnicas, possuem o mesmo compromisso: pintura, escultura, música, canto, drama, literatura. Todas elas estão assentadas sobre a teoria estética de Rasa, descrita no Natyasastra como a 'evocação de um sentimento ou a realização de um estado do ser' (Vatsyayan, 1968) e, portanto, também possuem os mesmos pressupostos éticos e estéticos de experiência com o sagrado através da experiência artística, como bem explicita Vatsyayan:

\footnotetext{
A mente Hindu vê o processo criativo como um meio de sugerir ou recriar uma visão, ainda que fugaz, de uma verdade divina; e considera a arte como meio de experimentar um estado de êxtase, parecido com o estado absoluto de ananda ou jivanmukti (libertação em vida). (Vatsyayan, 1968, p.3, tradução livre de Irani Cippiciani).
}

A dança, neste contexto, talvez seja, dentre todas as outras as outras formas de arte, a que consegue reunir mais elementos propiciadores desta experiência com a 'verdade divina' de que Vatsyayan nos fala. Isso porque ela consegue, de modo muito coeso e harmônico, reunir praticamente todas as outras formas de arte em seu bojo: o drama, a música e o canto, a escultura e a pintura presentes no corpo em movimento da bailarina, desenhando formas no tempo-espaço e a literatura oferecendo 
os conteúdos fundamentais à expressão do sentimento indiano, todas a serviço desta experiência de liberação e êxtase. Talvez isso explique porque razão, na atualidade, existem tantos estudiosos, pesquisadores e artistas, ocidentais e orientais, interessados em estudar as formas de dança clássica da Índia, pois nelas estão embutidos os saberes de diferentes formas artísticas numa síntese perfeita, resultado de centenas de anos de elaboração e reelaboração. Ainda segundo Vatsyayan:

[...] pode-se sugerir que na técnica da dança indiana a roda da teoria estética indiana parece ter se completado. Considerando que, em outras artes o ser humano é o assunto da criação artístico, a dança indiana trata a forma humana como um veículo de expressão artística e sintetiza em si o conteúdo e a forma das outras artes num todo homogêneo e belo. Não é por acaso que o dançarino Siva, Nataraja, representa a apoteose da fé espiritual e artística e o esforço das pessoas em alcançá-la. Esta imagem é o símbolo supremo de todos os aspectos da vida, tanto quanto a própria dança representa a síntese de todos os aspectos da atividade criativa (Vatsyayan, 1968, p.3, tradução livre de Irani Cippiciani).

Para concluir este artigo, apresentamos um trecho do diálogo do Rei Vajra e o sábio Markandeya descrito no Visnu-Dharmottara Purana, conforme segue na obra de referência Classical Indian Dance in Literature and the Arts, que de modo excepcional resume a importância da dança para a sociedade hindu e seu ethos:

Rei Vajra solicita ao sábio que o aceite como seu discípulo e lhe ensine a arte da feitura de ícones de modo que ele possa adorar as divindades em suas formas perfeitas. O sábio responde que não se pode compreender os princípios da criação das imagens sem o conhecimento da pintura. O rei deseja então obter instruções nesta arte e lhe é dito que, a menos que ele seja um habilidoso dançarino, não poderá compreender até mesmo os rudimentos da pintura. $\mathrm{O}$ rei pede então que lhe seja ensinada a arte da dança, ao que o sábio responde que, sem um grande senso de ritmo ou um conhecimento da música instrumental, a proficiência em dança é impossível. Mais uma vez o rei pede que estes assuntos lhe sejam ensinados; e o sábio lhe responde que o domínio da música vocal é necessário antes que se possa ser proficiente em música instrumental; e assim, finalmente, o sábio guia o rei por todos esses estágios antes que a ele seja ensinada a arte da iconografia (Vatsyayan, 1968, p.2, tradução livre de Irani Cippiciani).

\section{Referências}

ACHARYA, Rahul. A Systematic Analisys of Odissi Dance. In: www.narthak.com/info/ articles/article38.html, 2015.

ANTZE, Rosemary Jeanes. Exemplos Orientais. In: BARBA, E.; SAVARESE, N. (Orgs.). A arte secreta do ator: Dicionário de Antropologia Teatral. São Paulo: Hucitec; Campinas: Unicamp, 1995.

BHARATAMUNI. The Natya Sastra. Translated into English by a board of scholars. New Delhi: Sri Satguru Publications, 1986.

CAMPBELL, J. Mitos, Sonhos e Religião - Nas artes, na filosofia e na vida contempo- 
rânea. Rio de Janeiro: Ediouro, 2001.

COOMARASWAMY, Ananda. The dance of Shiva: Essays of Indian Art and Culture. Toronto: General Publishing Company, 1985.

ELIADE, Mircea. Imagens e Símbolos - Ensaio sobre o simbolismo mágico-religioso. São Paulo: Martins Fontes, 2002.

GAUHAR, R. The Dance Divine. N. Delhi: Niyogi Books, 2007.

GROTOWSKI, Jerzy. O teatro laboratório de Jerzy Grotowski. Tradução Berenice Raulino. São Paulo: Perspectiva, 2001.

HANNA, Judith Lynne. Dança, Sexo e Gênero. São Paulo: Rocco, 1999.

JHANJI, Rekha. Rasanubhuti and Brahmananda: Some parallels. In: SRINIVASAN, Amrit (Ed.). Approaches to Bharata's Natyasastra. New Delhi: Sangeet Natak Akademi and Hope India Publications, 2007. p. 90-104.

KARNAD, Girish. Preface. In: SRINIVASAN, Amrit (Ed.). Approaches to Bharata's Natyasastra. New Delhi: Sangeet Natak Akademi and Hope India Publications, 2007. P. ix-xi.

LATH, Mukund. The Path that Bharata did not Take. In: SRINIVASAN, Amrit (Ed.). Approaches to Bharata's Natyasastra. New Delhi: Sangeet Natak Akademi and Hope India Publications, 2007. p. 125-142.

MASSEY, R. The Dance of India: A general surveyand dancer's guide. London: Tricolours Books, 1989.

MOHANTY, K. The Odissi Path Finder Odissi Rechearch Centre Bhubaneswar In. s/d

PRONKO, Teatro Leste \& Oeste. São Paulo: Perspectiva,1986.

ROPA, E.C. A Dança e o Agit-Prop: Os Teatros Não Teatrais na Cultura Alemã no Início do Século XX. São Paulo: Perspectiva, 2004.

SAMSON, Leela. Rhythm in Joy. N. Delhi: Lustr Press Pvt Ltd, 1987.

SCHERER, Jacques. Bharata, a criação do teatro. In: BORIE, Monique et al. Estética teatral. Textos de Platão a Brecht. Tradução Helena Barbas. Portugal: Calouste Gulbenkian, 1996. P 31-38.

SHOVANA, Narayan. The sterling book of Indian Classical Dances. UK, USA, and ÍNDIA: New Dawn Press Inc., 2005.

SRINIVASAN, Amrit (Ed.). Approaches to Bharata's Natyasastra. New Dellhi: Sangeet Natak Akademi and Hope India Publications, 2007. 
SOARES, M.; ANDRAUS M.; WILDHAGEN J. (Orgs.). Mitos e Símbolos na Cena Contemporânea. Interlocuções oriente-ocidente. Jundiaí: Paco Editorial, 2014.

VATSYAYAN, Kapila. Classical Indian Dance in Literature and the Arts. New Delhi: Sangeet Natak Akademi, 1968.

Recebido em: 29/09/2015

Aprovado em: 05/02/2015 